\title{
7. Radio New Zealand International Reporting the Pacific in tight times
}

\begin{abstract}
Radio New Zealand International (RNZI) broadcasts from New Zealand into the South Pacific and is relayed to South Pacific listeners by their various national news services. In 2006, American academic Andrew M. Clark characterised the role of RNZI as 'providing a service for the people of the South Pacific' that also provided 'an important public diplomacy tool for the New Zealand government' (Clark, 2006). A decade on, this article evaluates the ongoing use and utility of RNZI as a taxpayer-funded voice of and from New Zealand, as a service for the diverse peoples of the South Pacific and as a tool of New Zealand's transnational diplomatic efforts. RNZI is still a key source of local and regional information and connection for the distinct cultures and nations of the vast South Pacific area, whose peoples have strong links to New Zealand through historical ties and contemporary diasporae living in the country. But, RNZI now faces mounting financial pressure, a government swinging between indifference and hostility to public broadcasting and questions of legitimacy and reach in the 'digital age'. With RNZI under pressure in 2016, key questions arise about its present and future. What is RNZI doing well and not so well? What role should New Zealand's domestic and international politics play in the organisation and its outputs? And how might its importance and impact be measured and understood in such a culturally and geographically diverse region as the South Pacific? Using a variety of sources, including documents released to the author under the New Zealand Official Information Act, this article explores the role of RNZI in the contemporary New Zealand and South Pacific media environments.
\end{abstract}

Keywords: broadcasting, diplomacy, DatelinePacific, international journalism, New Zealand, Pacific news, radio, Radio New Zealand International, RNZI

\author{
MATT MOLLGAARD \\ Auckland University of Technology
}

\section{Introduction}

ADIO New Zealand International (RNZI) is a news and current affairs radio service generated in Wellington, New Zealand and broadcast via shortwave, digital relay and online streaming into the South Pacific and 
beyond. Its key tasks are to provide timely, accurate, fair and balanced news, weather and current affairs to Pacific peoples, with a focus on the South Pacific. New Zealand provides this service as part of wider transnational aid and assistance it gives to South Pacific nations due to the strong ex-colonial and diasporic links between New Zealand and the Islands. While the service is based in New Zealand, it uses local reporters in the Pacific Islands to bolster its coverage of events as the need arises. This cultivation of local sources is an important ancillary role of RNZI, as it helps further its reach while also raising the level of journalistic endeavour in the region by promoting good reporting practices and open societies. RNZI is operated by Radio New Zealand, a commercial-free and taxpayer funded public radio service and has been broadcasting in one form or another since 1948. It also provides Pacific news and current affairs content to Radio New Zealand's other services, Radio New Zealand National (a current affairs and news service) and Radio New Zealand Concert (a fine music service).

RNZI's tax-payer funding is currently 'ring fenced' off from that of Radio New Zealand, being provided in a separate allocation by the Ministry of Culture $\&$ Heritage $(\mathrm{MCH})$, in order to guarantee a minimum level of funding inside the Radio New Zealand operation (W. Zweifel, personal communication, June 23, 2016). This demonstrates a unique and important role for the service, which is part of a wider New Zealand government strategy of engaging with the Pacific through multiple channels. Around 20 radio stations throughout the South Pacific islands rebroadcast the service, and its flagship daily news and current affairs show, Dateline Pacific, is also rebroadcasted on the London-based World Radio Network as well as broadcasters in the United States, Europe, Asia and the Middle East. Parts of the programme are also rebroadcast by the BBC's World Service in the Pacific Islands (Radio New Zealand International, 2016). ${ }^{1}$

According to a 2013/2014 RNZI report to the New Zealand government, more than 75 percent of people in the Pacific listen to RNZI via their own local broadcaster and/or through relays of programmes on the British Broadcasting Corporation's (BBC's) World Service Pacific stations. There was also significant use of internet streaming and replaying of programming through the internet, with 1.6 million pageviews of the RNZI website recorded in that year (Radio New Zealand International Audience Estimates, June 2014, p. 1). RNZI's services are complemented by the BBC service, but also the United States based Voice of America (VOA) and Radio Australia, which have a similar remit to present news and current affairs from the region. RNZI is used across the South Pacific as a news service for local radio stations and also carries specialised programming and long-form features that relate to events and peoples of the region. RNZI also plays a critical role in collating and broadcasting weather information for the region, which is susceptible to extreme weather events such as cyclones and other 
large storms. The service also plays a pivotal role in other civil defence emergencies, such as broadcasting tsunami warnings to the region, which has significant seismic activity as part of the Pacific 'Rim of Fire' tectonic plate activity zone. (Radio New Zealand International, 2016). Radio New Zealand International is therefore a critical and life-saving service for the peoples of the region and according to the RNZI website, it is 'well respected and widely listened to across the Pacific and beyond' (Radio New Zealand International, 2016).

\section{The South Pacific in context}

The South Pacific Islands are a diverse and atomized collection of nations spread over the vastness of the Pacific Ocean, generally south of the equator. These tropical and sparsely populated islands were some of the last settled land masses of global human migration and still feature some of the most isolated cultures on Earth today. During the period of European and American colonial expansion, all of the islands were claimed variously for France, the United Kingdom, Germany and The United States and others as missionaries, whalers, sealers, traders and eventually full colonial enterprises took over as these powers struggled for political, military and economic dominance in the region. These colonial enterprises are still noticeable today across a broad spectrum of outside influence and control over these island nations, with everything from virtually complete control over groups of islands (the French colonial outposts of New Caledonia, and French Polynesia among others) and so called 'free associations' such as those of the Cook Islands, Tokelau and Niue which are significantly funded by the New Zealand government and whose peoples can claim New Zealand citizenship. Some former colonies have won total independence from colonial administration since World War Two, with Fiji, Tonga and Western Samoa completely self-governed, but retaining significant connections through diasporae and economic links with the bigger states of Australia and New Zealand. English and French are still spoken in the colonies and ex-colonies and various Christian denominations are the dominant religions, often practised with vigour and local cultural inflections that date back to the early colonial days (Fraenkel, 2012).

The South Pacific is therefore still very much a region of influence of the traditional colonial powers, with recent developments such as the incursion of Chinese infrastructure and other funding and Russian military assistance to a growing number of small Pacific nations causing concerns in New Zealand and Australia. ${ }^{2}$ The United States has a significant military presence through the US Pacific Fleet in Hawaii and Marine Corps forward base outside Darwin, both of which counterbalance Russian and Chinese interests in the region. The South Pacific, while idyllic in the popular imagination, is still a contested space in the wider global framework of competition for resources such as fisheries, minerals, oil and arable land. 
The South Pacific is also dealing with the long-term effects of atmospheric and underwater testing of nuclear weapons from 1946 until 1996 by the United States, France and the United Kingdom (Robie, 2015; Watters, n.d.). Some restoration of damaged atolls and compensation has been made to displaced Islanders and those suffering from long term effects of nuclear fallout, island nations are still taking legal action in international forums in order to publicise the significant and ongoing health, societal and economic impacts of nuclear testing in the region (Buchanan, 2014).

Another pressing issue which complicated the geopolitical balance of influence in the region is the effect of climate change caused by global warming - with entire low-lying island groups and their populations (such as those of Kiribati) soon to be completely inundated by rising seas and increasingly being battered by more and more powerful cyclones and other adverse weather conditions. These issues are likely to force mass migration events, putting significant strains on nearby nations that are also feeling the effects of the loss of food-growing land, temperature-sensitive fisheries and potable water supplies, as they are threatened by encroaching seas (Finucane, Keener, Marra, Smith \& Spooner, 2012). The South Pacific faces major social, political and economic disruption in coming decades and will very likely become even more reliant on outside assistance from major players in the region such as the United States, China, Australia and New Zealand.

With these structures and issues in mind, this article examines the role and impact of Radio New Zealand International in its focus on and interactions with Pacific societies and cultures, but also its utility as an extension of the New Zealand government - political, diplomatic and economic policies in the South Pacific region.

\section{Radio New Zealand International in $\mathbf{2 0 0 6}$}

In 2006, American academic Andrew M. Clark characterised the role of RNZI as 'providing a service for the people of the South Pacific' that also provided 'an important public diplomacy tool for the New Zealand government" (Clark, 2006, p. 113). Clark was developing on his earlier study of Radio Australia's role in the wider Asia Pacific and in particular, the Melanesian region, where he demonstrated significant differences in the approach of the Australian and New Zealand governments' international broadcasting activities. Clark noted the different funding streams of the two broadcasters, with Radio Australia International funded out of the same budget allocations as the national commercial free public broadcaster, The Australian Broadcasting Corporation (ABC), and Radio New Zealand International funded until 2002 by the New Zealand Ministry of Foreign Affairs \& Trade and then by the Ministry for Culture \& Heritage (Clark, 2003, p. 97). 
These different funding agencies pointed to critical differences in the way the two governments approached these broadcasters, with Australia's service arguably less directed to the foreign policy and trade goals of the incumbent government than the New Zealand service until 2002. A change to MCH funding made RNZI's mandate different from that of earlier administrations, causing potential tensions when reporting fractious Pacific issues such as political infighting and corruption in a more independent environment (Clark, 2003, pp. 97-8). In Clark's 2006 estimation, RNZI had remained closely aligned with the diplomatic goals of the New Zealand government, while carefully treading a fine line of reporting accurately on serious Pacific issues (such as military coups in Fiji) that put critical pressure on New Zealand's relationships with its Pacific neighbors (Clark, 2006, pp. 112-3).

Clark also noted in 2006 RNZI's 'value and utility' in providing 'capacity to engender goodwill and put the New Zealand government in the best possible light' while providing a role model of open media systems and highly professional independent reporting practice for aspiring Pacific journalists and emergent media organisations in the region (Clark, 2006, pp. 111-3). This also extended to training Pacific broadcasters as the region's media outlets struggled with 'precarious' finances (Clark, 2006, p. 112). RNZI had also suffered from 'halfhearted commitment and continuous rounds of budget cuts over the years, although there was cause for optimism in 2006, with a more supportive leftleaning and internationalist Labour-led administration in government at the time (Clark, 2006, p. 113). This situation is now revisited after 10 years in order to evaluate the ongoing contribution and contemporary position of RNZI in New Zealand's broadcasting and diplomatic operations.

\section{Radio New Zealand International and the National-led government}

In November 2008, the centre-right, National-led coalition won government from the three-term, Labour-led administration. The new government had campaigned on a platform of reduced government, reduced taxes and no significant changes to funding for most branches of the state, including broadcasting (National Business Review, July 7, 2008). This had the effect of freezing and also reducing funding across state activities in broadcasting, including Radio New Zealand International. This policy has seen a measurable decline in funding for the service, as inflation has hit bottom-line costs for RNZI and the other state broadcast operations in the Radio New Zealand stable. This dwindling resource base has been further eroded by more recent directives from the Minister of Broadcasting, through the Board of Radio New Zealand for RNZI to operate with reduced funding of $\$ 50,000$ a year since 2013 , despite already running at unplanned deficits of $\$ 109,000$ in $2012 / 2013^{3}, \$ 26,000$ in 2013/2014 (Ministry for Culture \& Heritage, 2014) and $\$ 66,000$ by June 2015 (Ministry for Culture \& Heritage, 2015). 
These reductions and deficits exacerbate an already tightening fiscal situation. There has been a notable reduction in funding for RNZI when comparing the 2008-2009 and the 2014-2015 financial years. RNZI received total funding in 2008-2009 of $\$ 2,284,000$ while spending $\$ 2,237,000$ for a surplus of $\$ 47,000$ for the year (Radio New Zealand Annual Report 2008-2009). This compares with RNZI receiving total funding in 2014-2015 of \$2,224,000 while spending $\$ 231,000,000$ for a deficit of $\$ 88,000$ (Radio New Zealand Annual Report 20142015). This decrease in funding, coupled with increasing costs is not offset by any reduction in services or broadcast outputs over the period, with measures such as total hours of original Pacific programming actually increasing across the period (Radio New Zealand Annual Report 2008-2009 \& 2014-2015). There is no reason given for these funding reductions in material sourced under the Official Information Act, public statements of responsible Ministers, the Radio New Zealand management group or public documentation such as Radio New Zealand's annual reports for the period. It must then be assumed that the reductions are part of the overall freeze on funding for Radio New Zealand and other state broadcasting activities and as such, are attempts to move resources to other $\mathrm{MCH}$ activities to cover shortfalls elsewhere. The General Manager of RNZI, Linden Clark, was moved into a human resources management role at Radio New Zealand in June 2016, with ongoing oversight of RNZI as part of her portfolio of responsibilities (Thompson, 2016). According to RNZI news editor Walter Zweifel, Clark had been seconded to Radio New Zealand to head up a review of its music offerings for some time before taking on the new role, while still being paid out of the RNZI funding allocation. It was not clear if this situation had changed with Clark moving into the new role, with the return of the wage costs of Clark to RNZI to fund its own team, which would provide significant extra capacity for RNZI's operations in a time of dwindling budgets (W. Zweifel, personal communication, June 23, 2016).

\section{Radio New Zealand International and international diplomacy}

According to documents released to the author under the New Zealand Official Information Act in late 2015, there has been a notable amount of discussion between government ministers and departments about the role of Radio New Zealand International in recent years. In particular, there is a renewed focus on relationships with New Zealand's Pacific neighbours and the use of media generated in New Zealand to enhance and deepen connections through news and current affairs activity on RNZI, but also through providing more content through online platforms and the potential of televised sport such as rugby, a key sport for Pacific and New Zealand peoples alike (Broadcasting to the Pacific, n.d.).

Interestingly (and disappointingly), there is quite thorough redaction of many documents that deal with RNZI's role in New Zealand's diplomatic efforts in 
the region - especially those that feature discussions between the organisation's management, the Ministry for Broadcasting and the Ministry for Foreign Affairs and Trade. This is typical of the National-led government, which, as noted by increasing numbers of journalists and academics, has used exceptions to releasing information in the Act (such as the one used in these documents - national security), to severely delay, overly redact or otherwise limit information releases (Mediawatch, 2015). This got to the point that the Act's overseer- the Office of the Chief Ombudsman - was called in to investigate multiple complaints about information being withheld by Ministers and departments, with a subsequent report from the office showing large and unhelpful variations in compliance and freedom of information across government activities (Wakem, 2015, Politik, 2015).

Despite this, enough information can be gleaned from the documents to see the ongoing expectation of RNZI playing a part in New Zealand's diplomatic efforts in the South Pacific. This can be seen as a tranche of New Zealand's diplomatic modus operandi of exercising what Joseph Nye (1990) termed 'soft power' - the use of 'communications, organisations and institutional skills' in order to achieve political goals in international relations (Nye, 1990, p. 1578 ). Nye, who originally developed the theories of soft power, pointed to radio broadcasting as a key technology in expanding political views beyond national borders, using the United States international radio service Voice of America (VOA) as an example of the utility of radio in reaching across national, linguistic and political boundaries as a means of persuasion, attraction and information sharing that projects national power in non-military ways (Nye, 2004, pp. 4-6). According to Hoadley (2007), New Zealand is a prime example of a 'progressive small state' that has capitalised on the use of soft power-relying on 'respect, trust, admiration, persuasiveness, and leadership rather than compulsion by an armed force or a dominant economy' to promote security and stability in its region (Hoadley, 2007, p. 19). This is what Andrew Clark observed of Radio New Zealand International's work in 2003 and 2006, which is also evident in these (albeit, heavily redacted) documents.

One example is a Ministry for Culture \& Heritage report titled Broadcasting to the Pacific: Future Role of RNZI. This report was received with no indication of author(s), destination(s) or subsequent actions and is significantly redacted. However, it does cover a 'timeframe' for action and also discussions with the Minister of Broadcasting, 'senior members of the New Zealand broadcasting industry', 'officials from the Ministry of Foreign Affairs \& Trade (MFAT)' and a meeting with Television New Zealand (Broadcasting to the Pacific, n.d. p. 1). Judging by the tone, content and those consulted, this would seem to be a document generated by the Ministry for Culture \& Heritage.

These discussions were to 'determine whether, for cultural and diplomatic 
purposes, RNZI's current level of service to South Pacific listeners should be maintained' (Broadcasting to the Pacific, n.d. p. 1). The operative word seems to be 'should' here, and the inclusion of 'senior members of the New Zealand broadcasting industry' and the public television broadcaster would imply a deep and thorough evaluation of the role that RNZI was playing in attaining wider government goals in the region. The report notes discussions around providing RNZI services through online delivery platforms, but concludes that 'it is unlikely that local infrastructure in the South Pacific has reached a stage where it can provide the same level of coverage as the current analogue shortwave service' (Broadcasting to the Pacific, n.d.). This acknowledges the relative lack of internet services in the Pacific Islands and the restrictively high cost of those available for media content delivery. The report also states that 'RNZI's role has diplomatic and economic, as well as cultural implications', necessitating the involvement of MFAT in any decisions made (Broadcasting to the Pacific, n.d. p.2). Further discussion acknowledges the ongoing importance of RNZI and also a 'work programme' at MFAT to 'provide sports programming to Pacific Island nations' through a new service. MFAT said that once operational, it would be 'interested in exploring possibilities for providing RNZI content' (Broadcasting to the Pacific, n. d., p. 2). This document firmly frames RNZI as part of the wider diplomatic apparatus of the New Zealand government, in which 'cultural' outputs seem secondary to 'diplomatic and economic' concerns under the current administration.

RNZI news editor Walter Zweifel also notes the soft power potentials of Radio New Zealand in its reporting on conflicts in the region (Zweifel, personal communication, 2016). Of particular importance is RNZI's independence and accuracy in dealing with sources and reporting facts in a measured and responsible manner (Zweifel, 2010, pp. 70-1). This means that RNZI - and by extension - the New Zealand government and its agents can be seen as trusted parties in these tense and volatile conflagrations (Zweifel, personal communication, 2016).

This was particularly important in New Zealand's involvement in the deescalation of a major conflict on Bougainville Island during the 1990s, as a decade-long civil war between rebel Islanders and the government of Papua New Guinea spilled over into nearby Solomon Islands (Zweifel, 2010, p. 70). RNZI's careful cultivation of sources and frank but reliable reporting helped to secure negotiations in which New Zealand played a key part as a host of talks between the warring parties and then a key monitor of the subsequent truce, by providing unarmed peacekeepers to help stabilise the nation (Zweifel, personal communication, 2016). Here Zweifel points to the power of RNZI as not just a reliable source of information, but also as part of the good Pacific citizenship New Zealand wishes to demonstrate in the region, with an open media and other highly functional democratic institutions setting a good example for nations emerging from decolonisation and constructing self-governance in various forms. 


\section{At the coalface: Radio New Zealand International on-air in $\mathbf{2 0 1 6}$}

However, Radio New Zealand International's output is not so neatly aligned with New Zealand's diplomatic goals and at times would seem to be working at cross-purposes with the smooth and unified application of soft power by the New Zealand government in engaging with its Pacific neighbours. RNZI is first and foremost an independent news service, created daily by a dedicated team of highly-trained professional journalists and producers, who constantly demonstrate freedom from direct government interference in their output. This is in stark contradiction to many national news services in Pacific nations, with countries like Fiji practising heavy censorship of the media by statute and others such as Tonga and West Papua New Guinea routinely and severely restricting free speech and journalistic endeavours that criticise power structures in those territories (Pacific Media Watch, 2016).

A brief survey of RNZI material previously broadcast and made available online in June 2016 shows RNZI's independent position on topical and controversial stories from the region. Stories about ethnic tensions in Solomon Islands, political upheavals in Cook Islands, government fraud in Papua New Guinea and banning of corporal punishment in Samoan schools demonstrate a high level of professional and critical engagement with diverse Pacific communities and a breadth and depth of newsgathering in the region that is unique to RNZI (Radio New Zealand International, 2016, June 19, 21 \& 23). There is no indication of deference to the governments or other powerful players within these countries and all sources are treated fairly in terms of right of reply and inclusion in stories.

Zweifel relates a strong sense of pride in the professional and balanced reportage of RNZI staff and their in-depth knowledge of Pacific issues that allows them to tell richer stories for their listeners (Zweifel, personal communication, 2016). At the time of writing, one staff reporter had reduced his workload to parttime in order to complete a degree in International Relations at the University of Auckland, with the strong support of the organisation as it would add further to their capabilities in the region (Zweifel, personal communication, 2016).

\section{Changes in RNZI and the Ministry for Foreign Affairs and Trade relationship}

Zweifel reveals that there has been a change in the relationship between RNZI and the diplomatic arm of the New Zealand government, since it was decoupled from MFAT funding in 2002. Zweifel recounts a strained relationship 'in the ' 90 s, when they didn't really trust us', but only one minor incident of 'interference' from a staff member employed by MFAT to work with RNZI over 'toning down' coverage of industrial action in Vanuatu, which Zweifel refused to do (Zweifel personal communication, 2016). This downplays more serious threats to the future of RNZI in the late 1990s. In 1997 the Treasury proposed significant cuts to 
the service as part of wider government belt-tightening (Clark, 2006, p. 109). Then in 1998, the Minister for Foreign Affairs and Trade, Don McKinnon, threatened to close the service altogether as he thought it was wasting MFAT resources for little diplomatic benefit (Clark, 2006, p. 108). This was averted by RNZI discussions with the Minister that pointed out the utility of the service as a media and civil defence partner in the Pacific. This was backed by support and advocacy from the influential Commonwealth Broadcasters Association (of which RNZI was a long standing member) and a public pressure group called 'Save Radio New Zealand International' which published criticism of the move and lobbied the minister and the others in government and the opposition (Clark, 2006, p. 109-110). According to Zweifel, McKinnon later claimed to have 'saved' Radio New Zealand International from being disestablished (Zweifel, personal communication, 2016).

On the question of any direct influence of direction from the New Zealand government, Zweifel is unequivocal:

No, I have to praise government, we don't have to report to government, we don't get suggestions ... we are a truly independent radio station ... no interference, and you know, it's worth saying. (Zweifel, personal communication, 2016)

But, Zweifel contends that the relationship had 'cooled ... in the last 15 years', with less direct contact between the two organisations since their separation in 2002, meaning that MFAT was no longer keeping RNZI 'in the loop' or 'advised' about diplomatic issues, foreign policy and particular Pacific programmes and delegations. This is seen as not so much deliberate, but more a lack of engagement with RNZI due to competing pressures on MFAT as an organisation-to the point that RNZI sometimes knows more about important foreign visitors and events than MFAT (Zweifel, personal communication, 2016). Zweifel does not see the relationship as particularly problematic, but arguably slightly advantageous to RNZI in that 'they are not keeping us in the loop, but they are also not interfering with us (Zweifel, personal communication, 2016).

This would seem to somewhat contradict assertions at government level that 'RNZI's role has diplomatic and economic, as well as cultural implications' (Broadcasting to the Pacific, n.d., p. 2). However, this might also augur a new appreciation of the role of RNZI as a provider of content that is 'gifted' to New Zealand's South Pacific island partners and as an influential outlet for the New Zealand government's views on the region. This needs to be balanced with Zweifel's contention that RNZI is strongly independent and free from government interference. This would reaffirm Clark's 2006 assessment of the service as an unsuitable 'vehicle for promoting trade and foreign affairs issues' due to its 'fair and objective reporting' (Clark, 2006, pp. 112-3). 


\section{Radio New Zealand International's role in the South Pacific}

Radio New Zealand International fills a gap in South Pacific media and civil defence broadcasting coverage, providing news and emergency information services in critical situations to remote islands that are heavily reliant on accurate weather and other life-saving information, that cannot be generated locally. Again, this demonstrates New Zealand's commitment to the region and its willingness to be a good neighbour and a helping hand in times of trouble. This also extends to RNZI's ability to cultivate reliable sources and be a balanced voice in reporting on war and conflict in the region. This in turn reinforces New Zealand's diplomatic efforts and strengthens its hand in negotiations and monitoring of turbulent political situations.

It is also worth considering who would fill the void if New Zealand relinquished its position in Pacific broadcasting when considering the developing power structures and fault lines of the wider region. New Zealand's dominant position in South Pacific news services has kept other nations with different agendas out of the media choices in the region, which is advantageous to New Zealand's deep cultural, political and economic connections with the Islands. The economic power of China (and conceivably Russia) could well be brought to bear in new media services aimed into the region in support of wider political and economic goals. China has begun a new and more assertive phase of engagement with the region, typified by a comment in China's official Xinhua news agency commentary that China was pursuing a 'peaceful rise' and is developing 'growing international influence, particularly its clout in the Asia Pacific' (Xinhuanet, 2016).

At the moment, New Zealand enjoys relatively uncontested opportunities in news gathering, access and broadcasting in the region. To weaken or abandon this privileged position may provide impetus to other players, reducing New Zealand's influence considerably. This might also threaten the development of strong, independent media outlets in the region, with news services mimicking the well-documented state-controlled censorship of news being replicated in other players' international broadcast services. This would be coupled with a loss of appropriate professional journalism training based in democratic principles, stunting local independent journalism.

This is a concern when considering Radio New Zealand International's current funding reductions, which have also meant a reduction in technical broadcast capability. On 1 July 2016, Radio New Zealand International retired one of its two transmitters, meaning a reduction in programme times for many Pacific listeners, especially in the 'breakfast' time slot (Clark, 2016). According to Zweifel, this is a direct outcome of cost pressures, with a replacement to continue all services costing NZ\$1-2 million and therefore out of reach for the organisation (Zweifel, personal communication, 2016). Although RNZI retains 
'a mix of analogue shortwave, digital DRM shortwave, satellite, partnerships and online content delivery', there is a real service loss for listeners in the region with the decommissioning of the transmitter (Clark, 2016). Arresting this loss and funding Radio New Zealand International appropriately is critical to its ongoing performance and capacity to enhance the lives of the diverse peoples of the South Pacific, but also in projecting New Zealand's values into its own region and beyond.

\section{Conclusion}

Radio New Zealand International plays a pivotal role in sourcing and reporting reliable information for audiences in the Pacific Islands, New Zealand and elsewhere. It is a proudly independent news service, claiming to suffer little or no direct interference in its operations or outputs from the New Zealand government, even when this reporting could be seen to be potentially damaging to New Zealand's international diplomatic efforts. They are also an exemplar of democratic media freedoms in a region that has too few examples. This role is arguably as important as any attempt to turn the service into a 'mouthpiece' of the New Zealand government, however tempting that might be. Funding an accurate, fair and reliable news service in the Pacific is an appropriate application of New Zealand's 'soft power' approach to international affairs - demonstrating the benefits of a functional, dynamic and open democracy with a trade-based economy reliant on solid transnational partnerships and good international governance. Added to this ability to project preferred political settings into the region is RNZI's role in supporting journalists from Pacific countries in their efforts to provide accurate and timely information and to develop their journalistic practice. This 'capacity building' helps to strengthen local media outlets in the Islands, further enhancing democratic developments in the region. The critical involvement of a free, informed and engaged media is a continuing challenge for most nations of the Pacific. New Zealand has a significant and critical presence in the media of the South Pacific, which enhances the security and stability of the whole region.

\section{Notes}

1. For a detailed discussion of Radio New Zealand International's history, see: Clark, A. M. (2006). Radio New Zealand International: The voice of New Zealand, broadcasting to the Pacific, Journal of Radio Studies, 13(1), 102-115.

2. Russia donated a shipment of 20 containers of small arms and other military equipment as well as military trainers to Fiji in early 2016, in what has been described by foreign policy experts as 'an opening move in a battle for influence in the region'. Source:www. theguardian.com/world/2016/jan/22/secretive-shipment-of-arms-donated-by-russia-tofiji-raises-concerns 
3. RNZI is funded June to June for accounting purposes. There is wider discussion and some activism around the effects of the 'funding freeze' applied to Radio New Zealand, available through a public group protesting against the situation, Save Radio New Zealand. The group's website contains articles and links that cover the controversy well: www.saveradionz.co.nz/

\section{References}

Buchanan, R. T. (2014, November 24). South Pacific Islands prepoare to sue French government for $\$ 1$ billion over nuclear tests. The Independent. Retrieved June 15, 2016, from www.independent.co.uk/news/world/south-pacific-islands-prepare-tosue-french-government-for-1 billion-over-nuclear-tests-9879653.html

Clark, A. M. (2003). Your Asia-Pacific network: The use of Radio Australia by the Australian government. Pacific Journalism Review, 9(1), 80-100.

Clark, A. M. (2006). Radio New Zealand International: The voice of New Zealand, broadcasting to the Pacific, Journal of Radio Studies, 13(1), 102-115.

Clark, L. (2016, June 24). RNZI moves to a one-transmitter operation. Retrieved June 28, 2016, from www.radionz.co.nz/international/pacific-news/307195/rnzi-movesto-a-one-transmitter-operation

Doherty, B. (2016, January 22). Secret Russian arms donation to Fiji raises concerns of bid for Pacific influence. The Guardian. Retrieved June 22, 2016, from www. theguardian.com/world/2016/jan/22/secretive-shipment-of-arms-donated-by-russiato-fiji-raises-concerns

Finucane, M. L., Keener, V. W., Marra, J. J., Smith, M. H., \& Spooner, D. (2012). Climate change and Pacific Islands: Indicators and impacts: Report for the 2012 Pacific Islands Regional Climate Assessment (PIRCA). Washington: Island Press (pp. ix-xii). Retrieved June 13, 2016, from www.cakex.org/sites/default/files/documents/NCA-PIRCA-FINAL-int-print-1.13-web.form_.pdf

Fraenkel, J. (2012, November 16). Pacific Islands and New Zealand-New Zealand and the Pacific, Te Ara - the Encyclopedia of New Zealand. Retrieved June 20, 2016, from www.TeAra.govt.nz/en/interactive/36846/colonial-control-in-the-pacific

Harman, R. (2015, December 9). How ministerial advisers thwart the Official Information Act. Retrieved June 20, 2016, from http://politik.co.nz/en/content/politics/521/

Hoadley, S. (2007). From defence to security: New Zealand's hard power, soft power, and smart power. New Zealand International Review 32(5) (2007), 18-21.

NZPA. (2008, July 7). TVNZ's competitor welcomes Nats broadcasting policy. The National Business Review. Retrieved June 25, 2016 from www.nbr.co.nz/article/ tvnzs-competitor-welcomes-nats-broadcasting-policy-32831

Nye, J. S. (1990). Soft power. Foreign policy: Twentieth anniversary, 80(1), 153-71.

Nye, J. S. (2004). Soft power: The means to success in world politics. New York: Public Affairs.

Peacock, C. (2015, November 6). Getting it out in the open: Reviewing the OIA. Mediawatch. Retrieved from www.radionz.co.nz/national/programmes/mediawatch/ audio/201777171/getting-it-out-in-the-open-reviewing-the-oia

Radio New Zealand Annual Report 2008-2009. (2009). Retrieved June 13, 2016, from: www.radionz.co.nz/assets/cms uploads/000/000/004/RNZ-Annual-Report-2009.pdf

Radio New Zealand Annual Report 2014-2015. (2015). Retrieved June 14, 2016, from: www.radionz.co.nz/assets/cms_uploads/000/000/074/RNZ_Annual_Report_2015.pdf Robie, D. (2015). Eyes of Fire: The last voyage of the Rainbow Warrior. [5th edition] Auckland: Little Island Press. Microsite: http://eyes-of-fire.littleisland.co.nz/ 
Thompson, P. (2016). Linden Clark appointment. [Email to RNZ and RNZI staff]. June 22, 2016.

Wakem, B. (DNZM). (2015). Not a game of hide and seek: Report on an investigation into the practices adopted by central government agencies for the purpose of compliance with the Official Information Act 1982. Retrieved November 29, 2016, from

www.ombudsman.parliament.nz/system/paperclip/document_files/document_files/1573/ original/not_a_game_of_hide_and_seek__review_of_government_oia_practices. pdf? $146655 \overline{5} 7 \overline{8} 2$

Watters, S. (n.d.). Nuclear-free New Zealand: Nuclear testing in the Pacific. Retrieved June 15, 2016, from www.nzhistory.net.nz/politics/nuclear-free-new-zealand/testingin-the-pacific

Zweifel, W. (2010). Reporting war: Covering the Pacific-Radio NZ International and West Papua as a case study. Pacific Journalism Review, 16(1), 68-71.

\section{Documents Released under the New Zealand Official Information Act}

Ministry for Culture \& Heritage. (n.d.) Broadcasting to the Pacific: Future Role of RNZI. Ministry for Culture \& Heritage. (2014). Direct funding of RNZ (RNZI) and TVNZ: SixMonthly Report.

Ministry for Culture \& Heritage. (2015). Radio New Zealand International six monthly report to 30 June 2015.

Radio New Zealand International. (2014). Radio New Zealand International audience estimates to June 2014.

\section{Websites}

Pacific Media Watch. Pacific Media Centre | Te Amokura Website. (2016). Retrieved June 22, 2016, from www.pacmediawatch.aut.ac.nz

Radio New Zealand International website. (2016). Retrieved May 29, 2016 from www. radionz.co.nz/international/about

Pacific News. Radio New Zealand International. (2016). Retrieved June 19, 21, 23, 2016, from www.radionz.co.nz/international

Xinhuanet. (2016, August 2). Commentary: Japan's defense white paper hypes up 'China threat' for hidden agenda. Retrieved August 5, 2016, from http://news.xinhuanet.com/ english/2016-08/02/c_135558121.htm

\section{Interview}

Zweifel, W. (2016, July 23). Personal communication.

Dr Matt Mollgaard is head of radio in the School of Communication Studies at Auckland University of Technology, New Zealand. He has a 25-year history in radio as well as more than 10 years as a radio academic and teacher. He has been researching, presenting and publishing on radio since 2005. He was the editor and a contributor to the 2012 book Radio \& Society: New Thinking for an Old Media. A preliminary version of this article was presented at the Radio Conference: Transnational Encounters in Utrecht, The Netherlands, in July 2016.

matt.mollgaard@aut.ac.nz 